\title{
Chronic lymphocytic leukemia in Kenya: an immunophenotypic and clinicopathologic study
}

\section{La leucémie lymphoïde chronique au Kenya : étude immunophénotypique et clinicopathologique}

\author{
E. Mulwa-Babu $\cdot$ D. Paresh $\cdot$ M. Riyat \\ Received: 13 March 2013; Accepted: 27 May 2013 \\ (C) The Authors. This article is published with open access at link.springer.com
}

\begin{abstract}
Objective: To define cases of chronic lymphocytic leukemia (CLL) by immunophenotypic criteria and describe the associated clinical features in patients diagnosed at Aga Khan University Hospital, Nairobi.

Background: Rising to the growing cancer challenge will require improved diagnostic services. CLL is common in elderly patients. The current international standard in diagnosis incorporates findings of immunophenotyping. Facilities for immunophenotyping have generally been unavailable in Kenya.

Method: A cross-sectional survey was conducted between August 2011 and April 2012. Potential cases were identified based on morphologic criteria. Consecutive samples were obtained and subjected to 3 colour immunophenotyping on a Cytomics FC 500 cytometer. CLL was defined using the Royal Marsden Hospital scoring system. Baseline clinical and diagnostic data were also obtained.

Results: Forty nine cases met the eligibility criteria. Thirty one were known CLL cases, and 18 were newly diagnosed. Median age at diagnosis was 62 years. Male:female ratio was $1.3: 1$. Black patients $(42 / 49)$ were more likely to present with high risk disease (Rai stages III-IV) and with higher lymphocyte counts than non-blacks at diagnosis. Twenty six point five percent of patients in this study were diagnosed in Rai stage 0 . The prevalence of CD5/ CD23 co-expression was found to be $95.9 \%$. CD5 was universally expressed, whereas CD23 was present in all but 2 cases. Both were associated with atypical morphology. Complete absence of light chain expression using a monoclonal antibody was found in $12.2 \%$ of cases. Five patients had their diagnosis revised. Of 31 patients on follow-up for
\end{abstract}

E. Mulwa-Babu $(\bowtie) \cdot$ M. Riyat

Department of pathology, Aga Khan University Hospital,

Nairobi, Kenya

e-mail : everlyne.mulwa@aku.edu

D. Paresh

Medanta AfriCare
CLL, only 5 had had any form of immunophenotyping done.

Keywords Immunophenotyping $\cdot$ Clinical features $\cdot$ CLL . Kenya

Résumé Objectif : Définir des cas de la leucémie lymphoïde chronique (LLC) selon les critères immunophénotypiques et décrire les caractéristiques cliniques associées aux patients diagnostiqués à l'hôpital universitaire d'Aga Khan de Nairobi.

Contexte : Combattre l'accroissement du cancer nécessite les services diagnostiques avancés. La LLC est fréquente chez les âgés. Une étude de l'immunophénotype, dont la capacité manque généralement au Kenya, est recommandée pour son diagnostic.

Méthode : Une enquête transversale fut faite entre août 2011 et avril 2012. Les échantillons des cas potentiels, selon les critères morphologiques, furent collectionnés et soumis à la cytométrie en flux 3 couleurs utilisant le cytomètre Cytomics FC 500. La LLC était définie par le Score Royal Marsden Hospital. Les données de base cliniques et diagnostiques furent aussi prises.

Résultats : Quarante-neuf cas furent inclus dont 31 déjà diagnostiqués et 18 de nouveaux cas. L'âge médian au diagnostic était de 62 ans. Le ratio homme/femme était 1,3/1. Les patients noirs (42/49) présentaient au diagnostic une maladie plus avancée (stades III-IV de Rai) et une lymphocytose plus élevée que chez les non-Noirs. $26,5 \%$ des patients présentaient un stade 0 . Tous les cas exprimaient le CD5. Tous exprimaient le CD23, sauf deux qui montraient une morphologie atypique : 95,9\% avaient le double marquage CD5/ CD23, 12,2 \% n'exprimaient pas des chaînes légères. Le diagnostic de cinq patients fut révisé. Seuls 5 des 31 patients avaient déjà profité d'une étude de l'immunophénotype.

Mots clés Immunophénotype Caractéristiques cliniques LLC $\cdot$ Kenya 


\section{Introduction}

The 2008 International Workshop on chronic lymphocytic leukemia (CLL) criteria and the $4^{\text {th }}$ edition of the WHO classification of hematolymphoid neoplasms incorporate immunophenotyping results into the diagnostic criteria for CLL $[1,2]$. A combined approach of immunophenotyping plus morphological evaluation improves diagnostic accuracy and hence appropriate therapy and prognostication [2,3]. CLL is known to occur in Kenya, but the occurrence of CLL when accurately defined by morphological evaluation plus immunophenotyping has not been described [4]. The typical CLL immunophenotype is a coexpression of CD5 and CD23 in monoclonal B cells with dim expression of surface immunoglobulin (sIg) and absent/dim CD79b (or CD22), and the absence of expression of FMC7 [1,5]. The Royal Marsden Hospital (RMH) scoring system, described by Matutes et al. [5] allows the distinction between CLL (RMH $=3-5)$ and other B-cell chronic lymphoproliferative disorders ( $\mathrm{RMH}=2$ or less). This study provides data on the diagnostic and clinical features of CLL at a tertiary referral hospital in Kenya.

\section{Methods}

\section{Study design}

A cross-sectional survey was conducted between August 2011 and April 2012. Patients were recruited serially.

\section{Study site}

AKUH,N department of pathology. The department serves the hospital plus a variety of outreach laboratories, independent laboratories and hospitals spread across Kenya.

\section{Study population}

All patients with persistent lymphocytosis $\geq 3$ months, consistent morphology and who gave consent were eligible for inclusion. Patients whose samples were unsuitable for immunophenotyping or with inadequate supplementary clinical information were excluded. Samples that obtained RMH scores $\leq 2$ were also excluded.

\section{Procedure}

Morphologic assessment was based on FAB criteria [6]. Cases were then categorized as typical or atypical morphology based on a consensus diagnosis between 2 pathologists. Consecutive samples were obtained and subjected to 3 colour immunophenotyping on a Beckman Coulter Cytomics FC 500 cytometer. A limited panel of antibodies was used. These included CD5, CD19, CD22, CD23, FMC7, kappa and lambda. CLL was defined using the scoring system described by Matutes et al. [5].

CD19 versus side scatter was the gating strategy used to identify the B lymphocyte cluster. Histograms were evaluated, and antigens were interpreted as positive/negative and as dim/bright positive where the intensity of expression mattered. Antigen positivity was defined as reactivity above isotype controls on $>20 \%$ of B cells as identified by flow cytometry. Dim expression was defined when the B-cell cluster fell within 1 decalogue of the isotope control. Bright positivity was when the cell cluster fell $\geq 2$ decalogues of the isotope control [5]. Light chain restriction (marker of clonality) was defined by an abnormal kappa-lambda ratio of $>3: 1$ (kappa restricted) or $<1: 2$ (lambda restricted) [7]. Cases of CLL were defined as those with a score of $\geq 3$ [5]. The baseline clinical and diagnostic data were also obtained. Approval for the study was obtained from the institution's research and ethics committees.

\section{Data management}

Descriptive data are presented as tables, bar and pie charts. Statistical differences in medians were sought using the Mann-Whitney test. Differences in proportions were analyzed using the Chi Square $\left(\chi^{2}\right)$ test. A P value $<0.05$ was considered significant.

\section{Results}

A total of 49 patients were included in the final analysis. Thirty one patients known to have CLL/SLL and 18 patients with a new diagnosis of CLL/SLL were included. Of the 31 patients with an established diagnosis of CLL/SLL, only 5 patients ( $16.1 \%$ ) had had any form of immunophenotyping done. For patients already known to have the disease, all the parameters recorded other than morphologic category and immunophenotyping results were those found at baseline. These patients were included since CLL is currently considered an incurable disease and guidelines for diagnosis mandate that immunophenotyping be performed as part of the diagnostic workup (Table 1).

The mean, median and age range were $62.1,62$ and 4595 years, respectively (Fig. 1).

The majority of patients had a score of 5 and a minority scored 3 which are similar to what is described $[5,8]$. The relative proportion of scores obtained was, however, distorted by the fact that 6 cases were scored on 4 points 


\begin{tabular}{|c|c|}
\hline Characteristic & Number (\%) \\
\hline \multicolumn{2}{|l|}{ Gender $(N=49 ; \mathrm{M}: \mathrm{F}$ ratio $=$} \\
\hline \\
\hline Male & 28/49 (95\% C.I $43.3-71 \%)$ \\
\hline Female & $21 / 49$ (95\% C.I $29-56.7 \%)$ \\
\hline \multicolumn{2}{|l|}{ Race } \\
\hline African & $42(85.7)$ \\
\hline Asian & $4(8.2)$ \\
\hline Caucasian & $3(6.1)$ \\
\hline Lymphadenopathy & $29 / 49(59.2)$ \\
\hline Splenomegaly & $25 / 49(51.0)$ \\
\hline Hepatomegaly & $8 / 49(16.3)$ \\
\hline Presence of any B symptom & $14 / 49(28.6)$ \\
\hline Night sweats & $10 / 49(20.4)$ \\
\hline Weight loss & $5 / 49(8.5)$ \\
\hline Extreme fatigue & $1 / 49(2.0)$ \\
\hline \multicolumn{2}{|l|}{ Haemoglobin level (g/dL) } \\
\hline \multicolumn{2}{|l|}{ Mean $=11.4(\mathrm{SD}=2.67)$} \\
\hline$<11 \mathrm{~g} / \mathrm{dL}$ & $18 / 49(36.7)$ \\
\hline$\geq 11 \mathrm{~g} / \mathrm{dL}$ & $31 / 49(63.3$ \\
\hline \multicolumn{2}{|l|}{ Thrombocytopenia $\left(\times 10^{9} / \mathrm{L}\right)$} \\
\hline \multicolumn{2}{|l|}{ Mean $=172.97(\mathrm{SD}=85.01)$} \\
\hline$<100$ & $9 / 49(18.4)$ \\
\hline$\geq 100$ & $40 / 49(81.6)$ \\
\hline \multicolumn{2}{|l|}{$\begin{array}{l}\text { Absolute lymphocyte count } \\
\left(\times 10^{9} / \mathrm{L}\right)\end{array}$} \\
\hline \multicolumn{2}{|l|}{ Median $=40.5$} \\
\hline \multicolumn{2}{|l|}{ Range (5.08-324.2) } \\
\hline \multicolumn{2}{|l|}{ Rai stage } \\
\hline 0 & $13(26.5)$ \\
\hline $\mathrm{I}-\mathrm{II}$ & $17(34.7)$ \\
\hline III-IV & $19(38.8)$ \\
\hline \multicolumn{2}{|l|}{ Binet } \\
\hline A & $23(46.9)$ \\
\hline $\mathrm{B}$ & $7(14.3)$ \\
\hline $\mathrm{C}$ & $19(38.8)$ \\
\hline
\end{tabular}

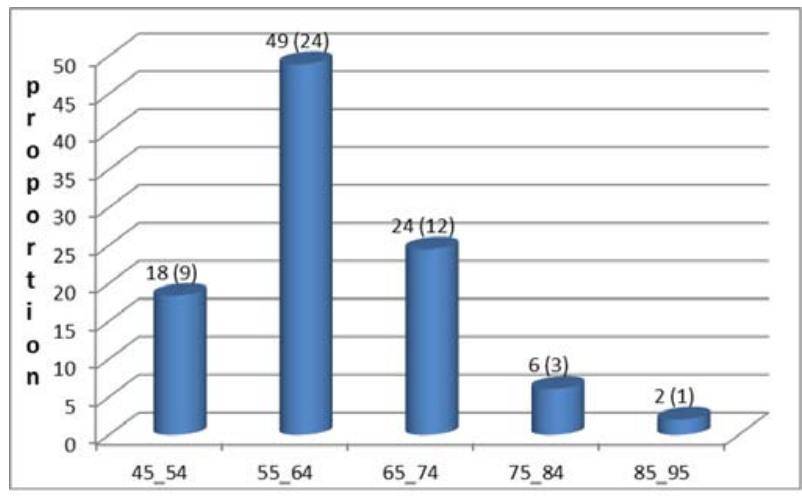

Fig. 1 Age distribution at diagnosis only due to absence of detectable light chains. This meant that the intensity of surface immunoglobulin ( $\mathrm{sIg}$ ) expression could not be assessed and light chain restriction could not be demonstrated. Five of these were assigned a score of 4 and one was assigned a score of 3 . CD5 was universally expressed, CD23 positive in $47 / 49$ and there was bright surface immunoglobulin (sIg) expression in 4/49 cases (Fig. 2) (Tables 2, 3).

\section{Discussion}

Twenty six point five percent of patients in this study were diagnosed in Rai stage 0 . In an earlier study on CLL in Kenya, no patient $(N=42)$ was found to present with lymphocytosis only [4]. This may reflect the increased use of automated complete blood counts. It may also point to an increased number of patients undergoing routine full haemogram as part of wellness checks. Similar trends have been observed in developed countries where the majority of their patients are now diagnosed as an incidental finding $[9,10]$.

The mean/median age was comparable to other African series $[12,13]$ but lower than that of developed nations $[11,14]$. This may be explained by the life expectancy of the population. The life expectancy in Africa is lower than that in Europe or North America, and this may create a selection bias that could explain the clustering of diseases at an earlier age. The youngest patient was 45 years old. An earlier series, also done in Kenya, had documented that at least 4 of 42 patients were in the age bracket 15-39 years [4]. CLL at that age is unusual [15] and their cases may represent rare cases or may reflect misdiagnosis due to unavailability of immunophenotyping facilities.

Racial differences were observed. It was noted that nonblacks were more likely to present with earlier stage disease and lower WBC counts than non-blacks and the difference was statistically significant (Tables 4,5 ). Though a similar observation has been previously noted, the reason(s) for this was not clear [16]. It could be that non-blacks had easier access to health care.

CD5/CD23 co-expression was found in 95.9\%. This immunophenotype excludes most reactive or clonal lymphoid disorders that could be confused with CLL. It is also reported to have a high positive predictive value in diagnosing CLL [8]. CD5 was found to be the most frequently expressed marker with $100 \%$ of cases expressing it. CD23 was expressed in all but 2 cases. Six cases (12\%) were scored on 4 points only due to the complete absence of detectable light chains. This aberrancy was attributed to a genuine absence due to changes in the epitope targeted by the monoclonal antibody used. The proportion of $12 \%$ which was obtained is close to that seen by Horna et al. 


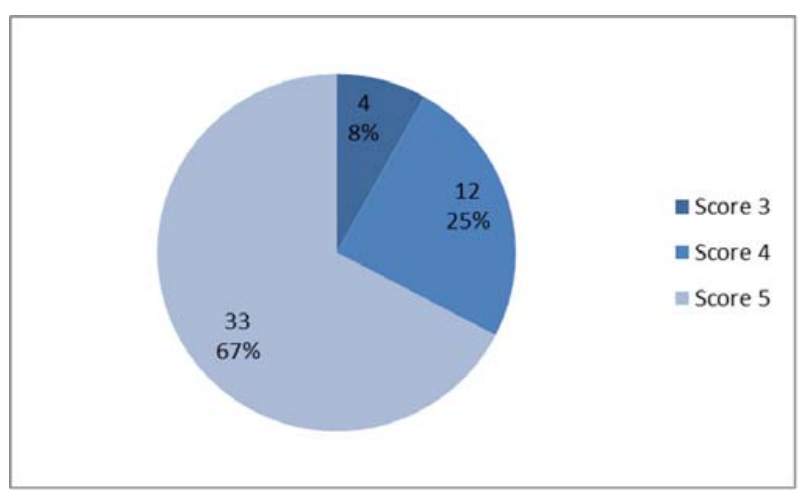

Fig. 2 Frequency of RMH scores obtained

[17] who described the absence of light chain expression in $13.2 \%$ of patients with CLL when a monoclonal antibody was used.

Of the 31 patients with an established diagnosis of CLL, only 5 patients had had any form of immunophenotyping done. This likely reflects the limited availability of these services in Kenya. Five cases had their diagnosis revised on the basis of morphologic and/or immunophenotypic criteria (Table 6).

\section{Conclusion}

Immunophenotyping is diagnostically productive and should be part of the diagnostic workup when a chronic lymphoproliferative disorder is suspected.

Ethical standards Approval for the study was obtained from the institution's research and ethics committees.

Conflict of Interest: E. Mulwa-Babu and D. Paresh do not have any conflict of interest to declare.

Open Access: This article is distributed under the terms of the Creative Commons Attribution License which permits any use, distribution, and reproduction in any medium, provided the original author(s) and the source are credited.

Table 2 Association between antigen expression patterns and morphologic subtype.

\begin{tabular}{|llllll|}
\hline Antigen expression & & Typical, $\boldsymbol{N}(\mathbf{\%})$ & Atypical, $\boldsymbol{N}(\mathbf{\%})$ & $\chi^{\mathbf{2}}$ & P value \\
\hline \multirow{2}{*}{ SIg } & Absent & $6(17)$ & $0(0)$ & 3.39 & 0.18 \\
& Bright & $2(6)$ & $2(14)$ & $12(86)$ & 0.36 \\
FMC7 & Dim & $27(77)$ & $12(86)$ & 0.04 \\
CD22 & Absent/partial & $32(91)$ & $2(14)$ & $13(93)$ & 0.55 \\
& Positive & $3(9)$ & $1(7)$ & 5.21 \\
CD5/CD23 & Absent/dim & $33(94)$ & $12(86)$ & 0.02 \\
& Bright & $2(6)$ & $2(14)$ & \\
\end{tabular}

Table 3 Association between treatment status, morphology and immunophenotype.

\begin{tabular}{|c|c|c|c|c|}
\hline & & Treated & Untreated & $P$ value \\
\hline \multirow[t]{2}{*}{ Morphology } & Typical & 15 & 20 & 0.365 \\
\hline & Atypical & 8 & 6 & \\
\hline \multirow[t]{3}{*}{$\operatorname{sIg}^{\mathrm{a}}$} & Absent & 3 & 3 & 0.655 \\
\hline & Bright & 1 & 3 & \\
\hline & Dim & 19 & 20 & \\
\hline \multirow[t]{2}{*}{ FMC7 } & Absent/partial & 22 & 22 & 0.203 \\
\hline & Positive & 1 & 4 & \\
\hline \multirow[t]{2}{*}{ CD22 } & Absent/dim & 23 & 23 & 0.093 \\
\hline & Bright & 0 & 3 & \\
\hline \multirow[t]{2}{*}{$\mathrm{CD} 5 / \mathrm{CD} 23$} & $\mathrm{CD} 5+/ \mathrm{CD} 23+$ & 23 & 24 & 0.174 \\
\hline & CD5+/CD 23- & 0 & 2 & \\
\hline
\end{tabular}


Table 4 Median hematologic parameters against race and clinical stage.

\begin{tabular}{|c|c|c|c|c|}
\hline & Median (IQR) & Median (IQR) & & \\
\hline Race & Africans (42/49) & Non-Africans & $P$ value & \\
\hline Haemoglobin & $11.6(9.4-13.3)$ & $13.9(12.7-14.1)$ & 0.02 & \\
\hline WBC count & $54.2(32.1-96.7)$ & $24.6(17.7-35.4)$ & 0.01 & \\
\hline ALC & $44.8(25.7-76.1)$ & $18.6(9.6-23.9)$ & 0.005 & \\
\hline Platelets & $138.0(106.0-218.0)$ & $265.0(198.0-312.0)$ & 0.003 & \\
\hline Rai stage & $0(13 / 49)$ & I + II (17/49) & III + IV (19/49) & $P$ value \\
\hline Haemoglobin & $13.5(11.8-14.1)$ & $13.0(12.4-13.9)$ & $9.4(8.6-9.8)$ & $<0.01$ \\
\hline WBC count & $32.3(21.8-40.7)$ & $46.1(19.6-97.4)$ & $66.0(44.0-97.7)$ & 0.03 \\
\hline ALC & $25.7(16.6-35.0)$ & $34.2(13.2-92.5)$ & $51.4(37.7-93.9)$ & 0.02 \\
\hline Platelets & $221.0(174.0-265.0)$ & $164.0(141.0-238.0)$ & $108.0(69.0-144.0)$ & $<0.01$ \\
\hline
\end{tabular}

Table 5 Association between gender, race and clinical stage.

\begin{tabular}{|lllll|}
\hline & & Male (\%) & Female (\%) & P value \\
Rai stage & 0 & $7(25)$ & $6(29)$ & 0.42 \\
& I + II & $8(29)$ & $9(43)$ & $6(29)$ \\
Gender & III + IV & $13(46)$ & Non-African & P value \\
& & African (\%) & $4(57)$ & $3(43)$ \\
Rai stage & Male & $24(57)$ & $6(86)$ & 1.00 \\
& Female & $18(43)$ & $7(17)$ & 0.01 \\
& 0 & $16(38)$ & $14)$ \\
\hline
\end{tabular}

Table 6 Patients with altered diagnosis.

\begin{tabular}{|ll|}
\hline Initial diagnosis & New diagnosis \\
\hline 1 patient with CLL & Hairy cell leukemia \\
2 patients with chronic & CLL \\
lymphoproliferative disorders & \\
(CLPD)- ?follicular lymphoma, ? \\
CLL & Essential \\
1 case of CLL ${ }^{\text {a }}$ & thrombocythemia (ET) \\
& 1 case of acute \\
CLL & lymphoblastic leukemia \\
& \\
\hline a This was a new patient who was referred as a case of CLL. It \\
was unclear how the diagnosis had been made. The clinical pre- \\
sentation and further evaluation resulted in a diagnosis of ET.
\end{tabular}

\section{References}

1. Hallek M, Cheson BD, Catovsky D, et al (2008) Guidelines for the diagnosis and treatment of chronic lymphocytic leukemia: a report from the International Workshop on Chronic Lymphocytic Leukemia updating the National Cancer Institute-Working Group 1996 guidelines. Blood 111:5446-56
2. Swerdlow SH, Campo E, Harris NL, et al (2008) WHO Classification of Tumours of Haematopoietic and Lymphoid Tissues. IARC

3. Nelson BP, Variakojis D, Peterson LC (2002) Leukemic phase of B-cell lymphomas mimicking chronic lymphocytic leukemia and variants at presentation. Mod Pathol 15:1111-20

4. Oloo AJ, Ogada TA (1984) Chronic lymphocytic leukaemia (CLL): clinical study at Kenyatta National Hospital (KNH). East Afr Med J 61:797-801

5. Matutes E, Owusu-Ankomah K, Morilla R, et al (1994) The immunological profile of B-cell disorders and proposal of a scoring system for the diagnosis of CLL. Leukemia 8:1640-5

6. Bennett JM, Catovsky D, Daniel MT, et al (1989) Proposals for the classification of chronic (mature) B and T lymphoid leukaemias. French-American-British (FAB) Cooperative Group. J Clin Pathol 42:567-84

7. Batata A, Shen B (1993) Diagnostic value of clonality of surface immunoglobulin light and heavy chains in malignant lymphoproliferative disorders. Am J Hematol 43:265-70

8. Gujral S, Polampalli SN, Badrinath Y, et al (2009) Immunophenotyping of mature B-cell non Hodgkin lymphoma involving bone marrow and peripheral blood: critical analysis and insights gained at a tertiary care cancer hospital. Leukemia Lymphoma 50:1290-300

9. Call TG, Phyliky RL, Noel P, et al (1994) Incidence of chronic lymphocytic leukemia in Olmsted County, Minnesota, 1935 through 1989, with emphasis on changes in initial stage at diagnosis. Mayo Clin Proc 69: 323-8 
10. Rozman C, Montserrat E (1995) Chronic lymphocytic leukemia. N Engl J Med 333:1052-7

11. Dores GM, Anderson WF, Curtis RE, et al (2007) Chronic lymphocytic leukaemia and small lymphocytic lymphoma: overview of the descriptive epidemiology. $\mathrm{Br} \mathrm{J}$ Haematol 139:809-19

12. Nwannadi I, Alao O, Bazuaye G, et al (2011) Clinical and laboratory characteristics of patients with leukaemia in South-South Nigeria. Internet J Oncol 7:[Epub ahead of print]

13. Omoti CE, Awodu OA, Bazuaye GN (2007) Chronic lymphoid leukaemia: clinico-haematological correlation and outcome in a single institution in Niger Delta region of Nigeria. Int $\mathrm{J}$ Lab Hematol 29:426-32
14. Redaelli A, Laskin BL, Stephens JM, et al (2004) The clinical and epidemiological burden of chronic lymphocytic leukaemia. Eur J Cancer Care (Engl) 13:279-87

15. National Cancer Institute (2012) SEER Stat Fact Sheets: Chronic Lymphocytic Leukemia. http://seer.cancer.gov/statfacts/html/clyl. html

16. Nel T, Joubert G, van der Ryst E, Bester I (1998) Chronic lymphocytic leukaemia in the Bloemfontein academic hospitals. Cent Afr J Med 44:195-9

17. Horna P, Olteanu H, Kroft SH, Harrington AM (2011) Flow cytometric analysis of surface light chain expression patterns in B-cell lymphomas using monoclonal and polyclonal antibodies. Am J Clin Pathol 136:954-9 